\title{
Project
}

\section{Seeds for life: a successful collaboration for the collection, conservation and utilization of Australian native seed}

\author{
Steve Adkins ${ }^{1 *}$, Sarah Ashmore ${ }^{2}$, Philip Cameron ${ }^{3}$, Jason Halford ${ }^{3}$ and Leon \\ Beyleveld ${ }^{4}$ \\ ${ }^{1}$ The University of Queensland, Brisbane, Queensland, Australia; ${ }^{2}$ Griffith University, Brisbane, Queensland, Australia; \\ ${ }^{3}$ Brisbane Botanic Gardens, Mt Cootha, Queensland, Australia; ${ }^{4}$ Greening Australia Queensland, Brisbane, Queensland, \\ Australia
}

\begin{abstract}
The 'Queensland Seeds for Life Project (Q-SFL)' is collaboration between the Millennium Seed Bank Project (MSBP) of the Royal Botanic Gardens, Kew, United Kingdom and several Australian Institutes, including The University of Queensland. The purpose of the SFL program is to improve the conservation and restoration of plant biodiversity in Queensland. This will be achieved by the collection and long-term storage of seed (as well as DNA) from priority species and by the use of these species in scientific research and utilization programs. In the first phase, seed of $c$. 1,000 species of Queensland native plants have been collected with $c .750$ new to the MSBP. Germination tests have been completed for more than $c .600$ collections, improving the knowledge base for these species and raising the opportunity for sustainable utilization in our collaborations with the Australian Mining, Floriculture and Native Fruits Industries. Detailed experiments have resolved germination issues (e.g. seed dormancy) for 200 species within families and genera that have been notoriously difficult to germinate, providing better understanding and management of threatened species. Work has been undertaken on the conservation of recalcitrant species with storage and regeneration protocols being developed for a number of previously unstudied species. Under the Q-SFL project six PhD studies have been completed on topics such as native grass utilization, soil seed banks, seed dormancy, seed longevity, utilization of native fruits and long term germplasm storage using cryopreservation. Our plan for the future builds on improving the cooperative nature of our partnership so that our state team can work in a complementary fashion with those from other states and overseas to obtain effective outcomes.
\end{abstract}

\section{Introduction}

The Queensland Seeds for Life Project (Q-SFL) is engaged in creating and testing sustainable approaches to the conservation and utilization of Queensland's unique botanical diversity. It aims to collect and study seeds from some of the rich array of native Queensland plant species and to determine how best seeds can best be preserved and utilized. The Q-SFL builds on an already flourishing international partnership between the Royal Botanic Gardens (RBG), Kew and several leading Queensland organisations: Griffith University (GU), University of Queensland (UQ), Brisbane Botanic Gardens

*Corresponding author, e-mail address: s.adkins@uq.edu.au
(BBG), and Greening Australia Queensland (GAQ). Over the past six years, a healthy and productive partnership between members of this alliance has emerged through exchanges of staff, communication of research results and sharing of professional expertise as well as seed collections. In a new stage of collaboration, the alliance will vigorously pursue its overarching aim of conserving Queensland species as an invaluable and unique biological collection for research and technological innovation both now and into the future. It will also achieve its critically important goal of permanently securing Queensland's botanical diversity outside of its natural habitat (ex-situ) through the establishment of duplicate seed collections in Queensland and at RBG Kew. 
All research strategies and methodologies adopted by the alliance are those accepted by the international scientific community. All research is performed under the guidance of qualified experts and the methodologies used are subject to peer review and evaluation to a degree determined by the participating organisation. This project unites expertise from two leading research organisations in Queensland (GU and UQ), the peak botanical and taxonomic authorities in Queensland (EPA and BBG) and the peak NGO for managing and repairing native vegetation in Queensland (GAQ) with the world's largest initiatives in plant conservation and associated research (MSBP) at one of the world's leading botanic gardens (RBG Kew). This group combines an impressive array of scientific and research expertise with on the ground capacity and knowledge of native flora, its identification, documentation, collection, conservation and utilisation.

The social, environmental and economic benefits of this project are varied and wide and flow from the intellectual capital developed as well as the practical solutions generated by the international partners. Seed biology research allows for more native species to be used in land restoration and rehabilitation, in floriculture, horticulture and forestry. Plant reproductive biology research will promote conservation under a changing climate. Cryobiology and biotechnology research will promote conservation of tropical species under threat or of high horticultural value. Field collection will allow DNA sampling from vouchered plant specimens. The entire project is of invaluable service to various businesses across Australia state as well as supporting the viability of new business opportunities in the areas of carbon offsets, mandated revegetation and site rehabilitation. Finally, there are incalculable social benefits in reducing environmental degradation and restoring biodiversity throughout Australia.

\section{Background and Rationale}

The Q-SFL project grew in part from an innovative global initiative undertaken by RBG Kew whose mission is to ensure better management of the earth's environment by increasing knowledge and understanding of the plant and fungal kingdoms. The MSBP of RBG Kew aims to collect seed from the world's flowering plant species, initially from dryland habitats, by the year 2020. RBG Kew is dedicated to the conservation of the world's flora and has the capacity for routine processing and long-term storage of seed as well as research facilities for investigation of aspects of seed biology and storage. The MSBP works to provide scientific information towards a better understanding of the mechanisms involved in seed development, germination, dormancy, seed storage behaviour and the nature of desiccation intolerance in non-orthodox species.

The Q-SFL partners as well as the MSBP recognized that the need for Australian seed preservation is pressing: almost 23\% of Australia's flora is listed as threatened, a figure amongst the highest in the world. Queensland has the richest flora of any state or territory in Australia, including 7,811 native flowering plants (Henderson 2002). Of these, 1,368 species are considered to be under threat (representing $27 \%$ of Australia's threatened species). This is second only to Western Australia, where 2,310 (45\% of Australia's threatened species) species are considered to be under threat (Briggs and Leigh 1995; Henderson 2002). Queensland also has the highest proportion of highest priority bioregions in the country when viewed in terms of consolidating the national reserve system (Sattler and Williams 1999).

Queensland is a particularly important focus for species preservation. Thirteen bioregions have been defined for Queensland, each with a number of ecosystems being defined within them (Sattler and Williams 1999). Nine of these 13 bioregions have $35 \%$ or greater of their ecosystems endangered or of concern. The bioregions within Queensland, which have the greatest numbers of species considered to be threatened, are the wet tropics bioregion in North Queensland and several Southern coastal bioregions. These statistics are comparable with those of the South West region of Western Australia (Briggs and Leigh 1995). A large number of species are also under threat in the Cape York Peninsula and the Brigalow Belt bioregions of Queensland.

While conservation of the threatened Australian flora is vital, it is often hampered by the poor quality of the seed collected, a lack of knowledge about its preparation and storage, and germination requirements for a variety of end uses. The QSFL project addresses this need by ensuring the collection of high quality seed from selected priority species and, by undertaking research, to increase our understanding of their biology, particularly in regard to the steps of collection, processing, ex-situ storage, dormancy breakage and germination.

The need for proven protocols for biodiversity protection is also immediate: within Queensland the restoration of whole ecosystems is now a requirement, given 
the decline in vegetation coverage that has resulted from land clearing for agriculture, mining and other biotic and abiotic processes. Queensland ecosystem restoration programs are being undertaken through the Australian Mining Industry (AMI), the Natural Heritage Trust (NHT), the Sugar Package and the 'Catchments to Reef' programs.

In undertaking these restoration programs, however, participants often lack adequate information to ensure that what biodiversity remains is protected and or is properly restored when it has been lost. At the present time, only a limited number of native species have been collected and even fewer have been studied sufficiently to germinate them effectively. This severely restricts the quality of the biodiversity that can be returned into these restoration programs. Hence, the Q-SFL program aims to collect seed and perform rigorous research into its germination needs. The result of this process cannot help but inform and assist many of these on going restoration programs.

In summary: conservation of seed from priority species and ecosystems, together with an improved understanding of how to collect, store and germinate these seed for biodiversity management and land restoration programs is vital to the process of conserving and restoring Queensland's biodiversity. An earlier phase of the Q-SFL project initiated the collection and banking of long-term conservation collections of seed and their associated herbaria specimens from priority Queensland native species. During this phase, c. 1,000 species have been collected as seed, processed and banked in Queensland and $c$. 750 duplicate seed lots from have been sent to RBG Kew in the United Kingdom. For many of these species quality assessment and germination requirements have been determined. For some species, use in land revegetation has taken place.

The overall objectives of the SFL project are:

○ The undertaking of a seed collection from the Queensland native species and their long-term storage at the Queensland seed banks, with duplicate collections sent to RBG Kew.

○ Development of conservation biotechnologies (in vitro and cryo-storage) for recalcitrant Queensland native species.

- Implementation of seed biology research (to overcome dormancy and to appreciate speciesspecific longevity characteristics) for selected species to establish protocols for seed germination and storage of species valuable to land restoration and rehabilitation projects.

- Study of selected arid land native plant species for their response to climate change variables in an effort to identify plant types that may be most severely affected by environmental change.

- Development of a database of germination and storage requirements for Queensland native plants for use in land restoration and rehabilitation projects.

- Provision of tissue samples to the Australian DNA bank (Southern Cross University) for DNA extraction and conservation.

\section{Research and Development}

The overall objective of the Q-SFL program is to contribute comprehensively to the national strategies for conserving, restoring and commercially using Queensland's botanical diversity. To this end, the actual research is divided into two components covering both tropical and arid zone regional species.

The tropical zone component focuses on in vitro and cryo-biology research important for tropical species, orchids and native and commercial tropical fruit species. An overarching concern of this work is the conservation of Queensland's threatened species and their potential use in new horticultural crops.

The second component focuses on arid zone native species, their reproductive responses to environmental change, their germination biology, longevity in storage and utilization of seed.

The embedded activities of seed collection, processing, germination testing, seed storage, taxonomic identification, data-basing and dissemination of seed biology information is coordinated within this project using resources of all five organisations in the project. These activities underpin and facilitate the research activities.

\section{Conservation and Utilization of the Arid Zone Native Flora}

The Queensland flora comprises an estimated 8,000 named species, with a significant proportion endemic to the arid zone. A large number of these plant taxa are listed as threatened 


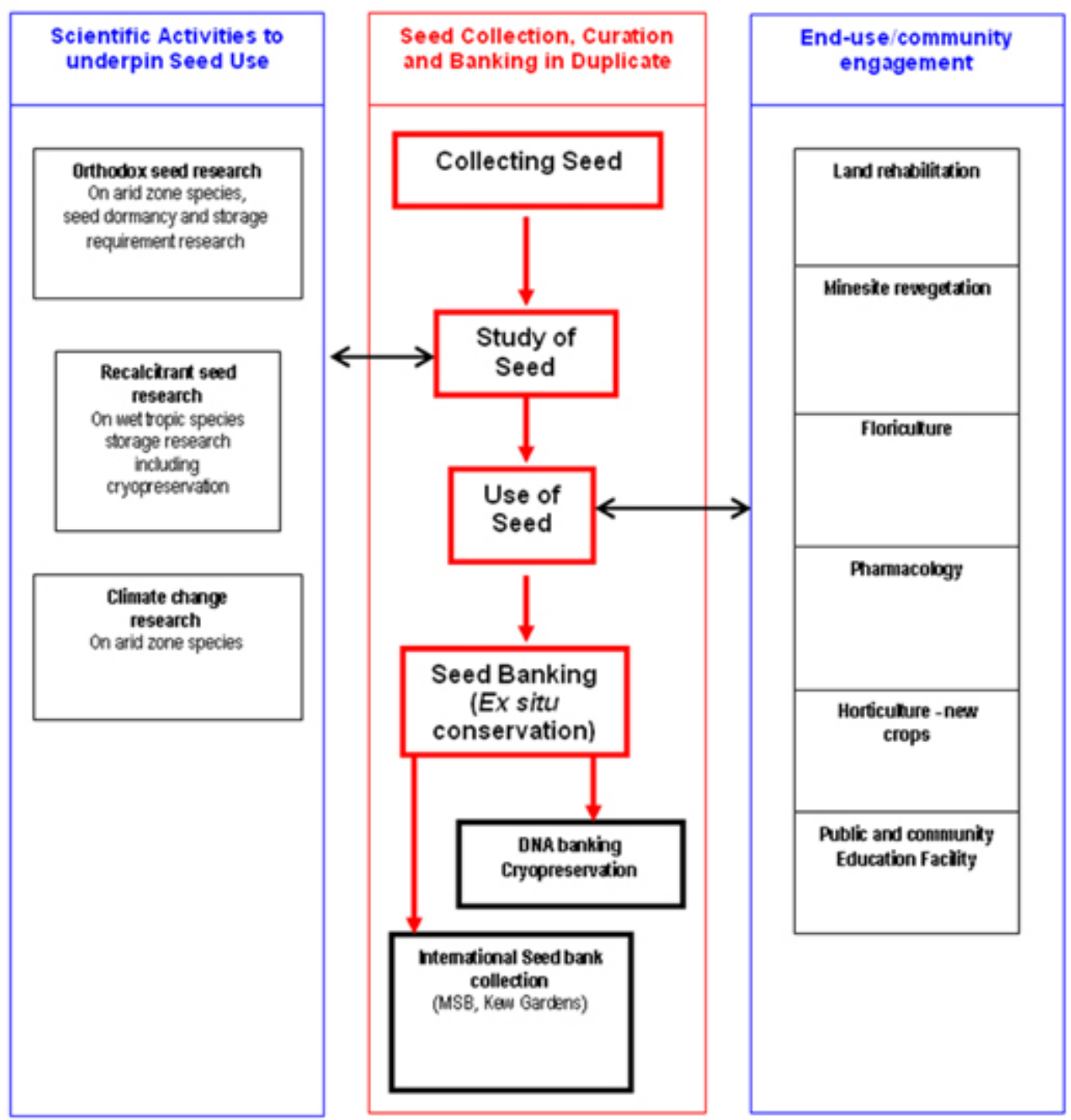

Figure 1. A schematic diagram of the 'Seeds for Life' project demonstrating how the seed collection, curation and banking activities interface with end user and community engagement activities as well as the science activities undertaken to underpin these seed use activities.

and could become extinct by 2050 unless remedial action is undertaken. In addition to these threatened taxa, large areas of these arid lands are ecologically degraded, or have been cleared or are experiencing erosion, rising water tables, salinity and/ or weed invasions. The restoration of these degraded landscapes is exacerbated by the low availability of native seed, the unreliable germination obtained from that seed, and the poor seedling recruitment achieved in the field (Allen $e t$ al. 2004). As a result, and similar to other states in Australia, many land care, restoration and threatened flora recovery programs fail to reach their full potential. Such programs are looking to seed scientists for continued supplies of high quality native seed and for solutions to the continued failure in recruiting species in land restoration programs. In addition to these restoration problems brought about by poor land management, over the next century human-induced climate change is expected to increase the rate of extinction. Thus, a scientific understanding of how the various species within the arid zone communities will be affected by climate change is urgently needed (Kriticos et al. 2003, 2004; Navie et al. 2005; O’Donnell et al. 2001). 
The objectives are to: (1) develop long-term ex situ conservation approaches for Queensland arid zone species and to investigate their seed biology characteristics to enable them to be rapidly and uniformly germinated in land revegetation projects; (2) to assess the effect climate change variables will have on the reproductive, germination and seed longevity characteristics of representative species; and (3) to examine other possible uses for native seeds viz. in native floriculture, pharmacology and gene bio-discovery. Thus, the overall aims of this component are to protect, secure and utilize the unique plant life found in Queensland's arid zones (Figure 1).

Outcomes: The outcomes include: (1) formulation of a series of unified research approach to the collecting and storage of Queensland native seeds and methods for the enhancement of their germination; (2) consolidation of a state research capability to ensure the protection of Queensland's arid zone native plant species for future generations; (3) enhancement of seedling recovery rates for improved land restoration outcomes; (4) promotion of diligent and efficient use of Queensland native seed for land restoration, conservation, floriculture and bio-discovery purposes.

\section{Long-term ex situ conservation and seed biology of arid} zone species (Objective 1): The wider use of Queensland arid zone native species will depend upon whether effective and efficient collection, processing and banking protocols can be developed for these species (Figure 1). The failure to reestablish plants from seed presently collected is due to a number of seed quality factors which include dormancy and low viability (Allen et al. 2004). The presence of dormancy, and/or a special requirement for germination, is the major reasons for poor, irregular seedling recruitment (Adkins et al. 2002). Thus, there is a great need to study the dormancy mechanism of key families and to apply the physiological knowledge obtained to the overcoming of dormancy in all species in those families (Adkins et al. 2002). In addition, family-specific information is required for the harvesting, processing and long-term storage of all the native species. This objective plans to collect up to 500 new conservation seed collections from the arid zone using the skills of a trained seed technologist, to access their quality, to study the dormancy mechanisms of representative species, to develop protocols for the germination of large batches of this seed (Adkins et al. 2001, 2003) and to be able to store seed of these species over long periods of time. The seed species to be collected will be determined by the needs of objectives 2 and 3. The research approaches to be used will include state of the art seed screening technologies (those of $x$-ray and nuclear magnetic resonance) to assess the seed; smoke chemicals (Adkins et al. 2001, 2003) and their analogues, and electromagnetic fields to overcome dormancy.

\section{Climate change variables and seed biology of arid zone} species (Objective 2): Current global species extinction rates are estimated to be many times greater than background levels (Department of the Environment and Heritage Australian Greenhouse Office). Until now, the dominant cause has been landscape change (habitat loss and degradation), however over the next century, human-induced climate change is expected to result in further large-scale, biodiversity loss. Queensland has significant vulnerability to the changes in climate projected over the medium to long-term, and our biodiversity is likely to be strongly affected by this climate change. Scientific evidence is mounting that the kinds of climate change expected will induce changes in species phenology, population dynamics and survival, habitat makeup, extinction rates, distribution of invasive species (O’Donnell et al. 2001; Kriticos et al. 2003, 2004; Navie et al. 2004, 2005) and other threatening processes. Such changes are already occurring in parts of Australia today. This objective plans to study up to 10 key species and to access their reproductive responses to the key climate change variables. The effect of increased temperature $\left(2\right.$ to $\left.6^{\circ} \mathrm{C}\right)$, reduced and increased soil moisture levels and elevated $\mathrm{CO}_{2}$ levels will be studied in pot-grown plants (Adkins et al. 1987; O’Donnell et al. 2001; Kriticos et al. 2003, 2004; Navie et al. 2005). This kind of work will be undertaken in specially modified growth rooms at UQ as well as in controlled environmental glasshouses. The species to be studied will represent community keystone species. The work on forbs and grasses will be taken past the point of seed production while the work on woody species will be focussed on vegetative, early stages of growth. The outcomes of the research will be used to prioritise seed collecting towards species that are most at risk.

Utilization of Queensland's arid zone native species (Objective 3): For many native species the gene sequences they contain and/or the chemicals that they produce may have as yet undiscovered uses. Certain gene sequences could be useful in creating new crops having, for example drought 
or salinity tolerances. Other plants with unique compounds in their parts might be useful for the creation of new pharmacological products, for example ones with antibacterial or fungal activity. Thus, there is a great need to conserve both the DNA from these plants as well as the intact seeds (from which new plants can be produced) for bio-discovery purposes. In addition to these kinds of uses, many arid zone species have unique floral characteristics that may make them a target for the native floriculture industry. Such species will only be useful to this industry if they too come with speciesspecific germination and seed storage protocols. Objective 3 plans to collect, using field-applicable technology, and to send DNA samples from all new encountered species to the Australian DNA Bank at SCU. Here it will be added to their expanding collection of Australian native plants and biodiscovery program. This objective also intends, with the help of staff from the CNF, to screen the collected new species for potential breeding materials for new floriculture products.

\section{Seeds for Health: An International Collaboration for the Collection, Conservation and Sustainable Utilization of Medicinal Plants from Nepal}

Nepal is very rich in medicinal plant biodiversity. However, various anthropogenic activities coupled with predicted climate change scenarios will be a threat to its survival of this diversity in the coming decades. Therefore, this high value plant biodiversity needs to be conserved for the long term and in order to generate national benefits for health and for poverty alleviation. In the consideration of these facts, an International collaborative project is underway in Nepal which in the long term will not only conserve the medicinal plant biodiversity in both a national and an international seed bank, but also will characterize many of them at the physiological, biochemical and molecular level. In addition, the research outputs in the disciplines of seed science and technology, biotechnology, molecular biology, biochemistry, taxonomy and ecology will then make possible the in situ sustainable utilization of this high value medicinal plant biodiversity for the well being and livelihood of Nepalese people. The Collaborating Institutions are the University of Queensland, Brisbane Australia, the Nepal Academy of Science and Technology, Lalitpur, Nepal, and the Central Department of Botany, Tribuvan University, Kathmandu.

\section{References}

Adkins S.W., Loewen M. and Symons S.J. 1987. Variation within pure lines of wild oats (Avena fatua) in relation to temperature of development. Weed Science 35: 169-172.

Adkins S.W. and Peters N.C.B. 2001. Smoke derived from burnt vegetation stimulates germination of arable weeds. Seed Science Research 11: 213-222.

Adkins S.W., Bellairs S.M. and Loch D.S. 2002. Seed dormancy mechanisms in warm season grass species. Euphytica 126: 13-20.

Adkins S.W., Peters N.C.B., Paterson M.F. and Navie S.C. 2003. Germination stimulation of weed species by smoke. In: The Biology of Seeds: Recent Research Advances (G. Nicolas, K.J. Bradford, D. Come and H.W. Pritchard, eds.), pp. 413420. CAB International.

Allen S.M., Adkins S.W., Preston C.A. and Bellairs S.M. 2004. Improved germination of the Australian natives, Hibbertia commutate, Hibbertia amplexicaulis (Dilleniaceae), Chameascilla corymbose (Liliaceae) and Leucopogon mutans (Eparcridaceae). Australian Journal of Botany, 52: 345-351.

Briggs J.D. and Leigh J.H. 1995. Rare or Threatened Australian Plants. Centre for Plant Biodiversity Research, CSIRO, Canberra, ACT, Australia.

Henderson R.J.F. (ed.). 2002. Names and Distribution of Queensland Plants, Algae and Lichens. Queensland Herbarium, Queensland Government Environmental Protection Agency, Australia.

Kriticos D.J., Sutherst R.W., Brown J.R., Adkins S.W. and Maywald G.F. 2003. Climate change and biotic invasions: a case history of a tropical woody vine. Biological Invasions 5: 147-165.

Kriticos D.J., Sutherst R.W., Brown J.R., Adkins S.W. and Maywald G.F. 2003. Climate change and the potential distribution of an invasive alien plant Acacia nilotica ssp. indica in Australia. Journal of Applied Ecology 40: 111124.

Kriticos D., Brown J.R., Maywald G.F., Radford I.D., Nicholas D.M., Sutherst R. and Adkins S.W. 2004. 'SPAnDX: A processbased population dynamics model to explore management and climate change impacts on an invasive alien plant, Acacia nilotica. Ecological Modelling 163: 187-208.

Navie S.C., Panetta F.D., McFadyen R.E. and Adkins S.W. 2004. Germinable soil seed banks of central Queensland rangelands invaded by the exotic weed Parthenium hysterophorus L. Weed Biology and Management 4: 154-167.

Navie S.C., Panetta F.D., McFadyen R.E. and Adkins S.W. 2005. The effect of $\mathrm{CO}_{2}$ enrichment on the growth of a $\mathrm{C}_{3}$ weed (Parthenium hysterophorus L.) and its competitive interaction with a $\mathrm{C}_{4}$ grass (Cenchrus ciliaris L.). Plant Protection Quarterly 20(2): 61-66.

O’Donnell C.C. and Adkins S.W. 2001. Wild oat and climate change: The effect of $\mathrm{CO}_{2}$ concentration, temperature, and water deficit on the growth and development of wild oat in monoculture. Weed Science 49: 694-702.

Sattler P. and Williams R. 1999. The Conservation Status of Queensland's Bioregional Ecosystems. Environmental Protection Agency, Brisbane, Australia. 